\title{
New histological finding in adamandiades-behçet's syndrome
}

\author{
Bacem A.E. Ottoman \\ Correspondence: bacemottoman@gmail.com

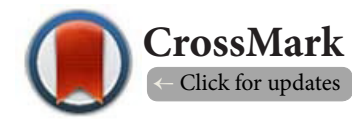 \\ Department of Maxillofacial Surgery and Diagnosis, Cairo University, Egypt.
}

\begin{abstract}
Characteristically pathognomonic findings are only those that can be evidently measurable at quiescent phases. Adamandiades-Behçet syndrome (or Behçet's disease) is a rare idiopathic multisystem disease of uncertain nature. Although the upper hand was usually given to autoimmunity, AdamandiadesBehçet syndrome (ABS) is, paradoxically, ANA negative. Autoantibodies do not play a major role in its pathogenesis, nor do B cells. Now that autoimmunity cannot full explain ABS, it is recently considered midway between autoinflammation and autoimmunity. There are no diagnostic laboratory tests for ABS, and laboratory fndings typically refect ongoing infammation. In this study, twelve clinically quiescent cases were scheduled for incisional labial salivary gland biopsies after testing positively for the pathergy test. The biopsies were microscopically examined to describe some characteristic findings, in contrast to normal mucosa. Four immunohistochemical markers were used: Cathepsin K, CD68, CD34 and CD16b. The immunohistochemical findings could provide decisive information in differentiating Behçet's disease from Crohn's disease because Cathepsin-K, a sensitive immunohistochemical marker for detection of micro-granulomas, is natively negative. These procedures are accordingly suggested to be integrated into a diagnostic protocol of Behçet's syndrome.
\end{abstract}

Keywords: Behçet's disease, minor salivary gland biopsy, dusty acini, new diagnostic protocol

\section{Introduction}

Behçet's disease is a multisystem idiopathic inflammatory vasculitis usually presenting with oral mucosa, ocular, articular, gastrointestinal and vascular manifestations. Gastrointestinal, neurological, and cardiac involvement are relatively infrequent [1].

In 1937, H. Behçet -a Turkish dermatologist-identified the three major signs (recurrent oral aphtae, genital ulcerations, recurrent hypopyon uveitis) and grouped them on a clinical entity, publishing a report in a German journal in 1937 [2] and pursued further to publish a successive article in 1938 in a French journal [3]. Later in 1939 and 1940, he called it the "triple symptom complex" [4].

Adamandiades-Behçet's syndrome was claimed to be triggered by either an autoimmune process, infectious or environmental agent (possibly local to a geographic region: old silk road), or in a genetically predisposed individual $[5,6]$. The interaction between a specific genetic background and environmental or infectious factors may contribute to the immune dysregulation that ripens, to an extent, this disease. Puzzlingly, ABS is always ANA negative. Autoantibodies do not play a significant role, nor do B cells. Accordingly, recent workup hopes to discover a new understanding in the pathogenesis of Adamandiades-Behçet syndrome that may help researchers set up a new treatment [7].

To date, no absolutely specific histologic, laboratory or imaging features are specific for diagnosing ABS. The Inter-national Study Group Criteria set is, therefore, the most widely used. Such criteria, still, have limitations, especially in diagnosing early $A B S$, or differentiating ABS from Crohn's syndrome (CS) [8-10]. Recently, the pathergy test, using a sterilized self-saliva, has been introduced toward more accurate and specific diagnosing ABS [11].

\section{Materials and methods}

Twelve volunteer cases were scheduled, after getting their informed consents in accordance with Helsinki declaration, to incise a labial minor salivary gland under local anesthesia (ring block anesthesia: 1:2 ml lidocaine) for conducting confirmatory results to exclude systemic granulomatous diseases and any other tests that might be relevant.

Aside from the sections which were obtained for the conventional H\&E histological staining to trace and scrutinize any 
characteristic features, serial sections from formalin-fixed, paraffin-embedded specimen blocks of $4 \mu \mathrm{m}$ thickness were deparaffinized in xylene and rehydrated in decreasing concentrations of ethanol. Endogenous peroxidase activity was blocked by immersing the sections in $3 \% \mathrm{H}_{2} \mathrm{O}_{2}$ with methanol for $30 \mathrm{~min}$. For antigen retrieval, sections were boiled in $10 \mathrm{mmol} / \mathrm{L}$ citrate buffer ( $\mathrm{pH} \mathrm{6.0)}$ for $15 \mathrm{~min}$ in a pressure cooker.

After treatment with protein block serum at room temperature, sections were covered with primary antibodies; Cathepsin K (3F9, Abcam, 1:300), CD16b, valuable in the detection of neutrophils (48kD, Polyclonal, Dako, Dilution 1:500), CD34, valuable in the detection of hematopoietic precursors, capillary endothelia (105-120kD, Polyclonal, Dako, Dilution 1:500) and CD 68 , strongly reactive antibody with virtually all cells of monocyte/ macrophage lineage [12], (110kD, Dako, Dilution 1:500). Immunoreaction was performed using the labeled streptavidinbiotin method and overnight incubation. For all antibodies, negativity or positivity was evaluated.

Furthermore, a total of 12 paraffin bocks, from archival cases of normal salivary glandular specimens, was sectioned, $4 \mu \mathrm{m}$ thickness, and processed as aforementioned to be similarly stained by CD16b, CD34, CD68 and Cathepsin-K.

\section{Results}

\section{Clinical findings}

Scrutinizing the records of the cases, all cases displayed positive C-reactive proteins, persistent, recurrent oral and genital ulcers, coagulopathy, ecchymosis from simple traumas, dizziness and frequent syncopes. Ten cases were positive when injected with sterilized self-saliva (Figure 1). The key findings are shown in Table 1.

Oral ulcers affected non-keratinzed and keratinized mucosa especially the labial mucosa and tongue. The commonest ocular manifestation was uveitis (Figure 2).

All cases showed ocular manifestations at a certain time; however, such manifestations ranged from mild redness, uveitis of a single or both eyes that could last for two to four months annually, usually aggravated in the winter. A singleeye-affection was encountered in five cases (the left eye). No blindness was reported in the interval of the study (Table 1).

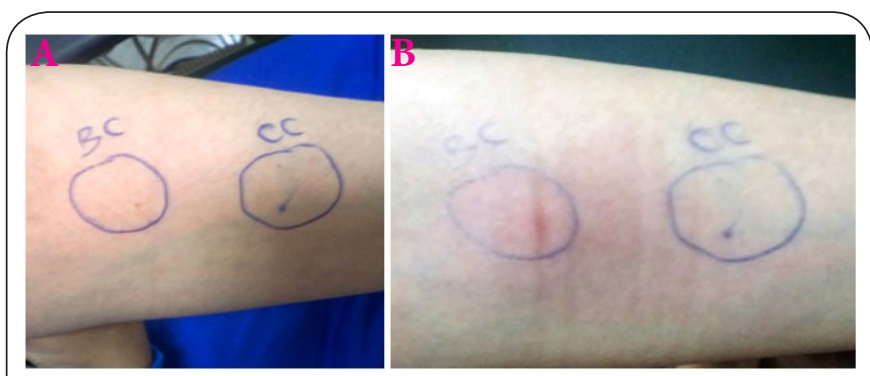

Figure 1. (A) Two circles were outlined to be injected with self-sterilized saliva and normal saline respectively (B) the same circles after 48 hours with remarkable erythematous interaction in the injected circle with self-sterilized saliva.

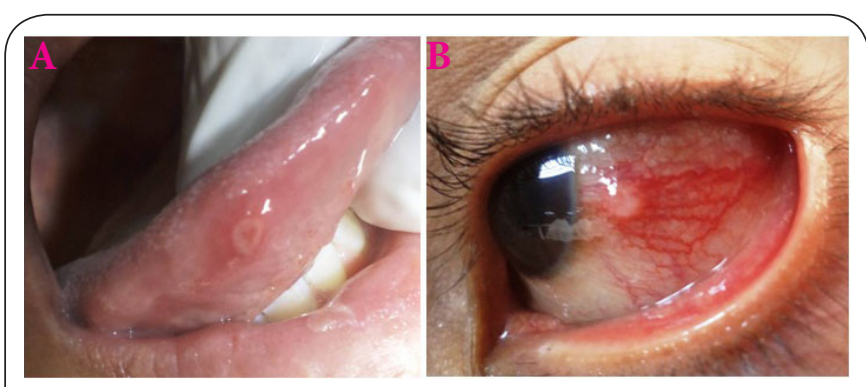

Figure 2. (A) Tongue ulcer at the lateral border with neither pertinent dental sharpness nor history of trauma. (B) Redness of the left eye.

Eleven cases showed elevated ESR but hepatic and renal profiles were quite normal. Two females had developed very large ovarian cysts $(3.2 \times 4.8 \mathrm{~cm}$ and $5.5 \times 3.7 \mathrm{~cm})$ on the sonographic imaging with thick echogenic wall and fine septations. Mild hepatomegaly was not uncommon (3/12). No patients have developed serious neurological manifestations. To exclude neuro-Behcet involvement and brain aneurysms, all patients have been assessed intercranially by MRI. Normal images were obtained (Figure 3).

Concerning treatment, all patients received the same treatment; hydrocorticosteroid tablets ( $60 \mathrm{mg}$ daily). Rheumatologists refused to recruit neither interferon nor TNF antagonist. These treatments have recently proved to be very effective. The efficacy of TNF antagonist, moreover, was observed in large case series and even in open studies but corticosteroid therapy is the mainstay treatment of $A B S$ in Egypt.

\section{Histological findings}

Since information about specific histopathological changes in Behcet's disease is scarce, this study tries to cast more light on this affect. The studied cases were contrasted to twelve archival sample of normal glandular mucosa as a control group.

Under ring-block local anesthesia ( $1.8 \mathrm{ml}$ of $2 \%$ Lidocaine), a normally appearing labial mucosa was vertically incised. A gentle dissection was aimed at harvesting approximately three minor salivary glands. The harvested glands were carefully picked and immediately placed into $10 \%$ formalin to be submitted to microscopic examination.

Slides of ABS revealed focal perivascular inflammatory infiltration of neutrophils, macrophages and some lymphocytes. The focal distribution was mainly periductal (Cf. Table 2).

Increased vascularity was observed, in contrast to normal mucosa whose vascular components were inconspicuous. Characteristic areas of massive hemorrhage as well as intervening extravasation of RBCs were evident, suggesting deterioration of the feeding blood vessels and capillaries. Evident in histological fields was also the appearance of the so-called "dusty acini", recapitulating the guise of the dust cells in smoking alveolitis. There appears to be macrophages-laden and mononcytes-laden acini. The macrophages are expected 
Table 1. Clinical parameters of the submitted cases.

\begin{tabular}{|c|c|c|c|c|c|c|c|c|c|}
\hline & Age & Gender & Oro-gen ulcers & CRP & ESR & Ocular manifestations & GIT & ANA & SSPT \\
\hline Case 1 & 58 & $\mathrm{M}$ & $\mathrm{Rec} / 3 \mathrm{ds}$ & + & $28 / 60$ & UVT (bilateral) & MoIP & - & + \\
\hline Case 2 & 62 & $\mathrm{~F}$ & $\mathrm{Rec} / 2 \mathrm{Ws}$ & + & $33 / 72$ & UVT (bilateral) & MdIP & - & + \\
\hline Case 3 & 38 & M & $\mathrm{Rec} / 5 \mathrm{ds}$ & + & $42 / 88$ & UVT (Left eye) & SIP & + & + \\
\hline Case 4 & 24 & M & $\mathrm{Rec} / 9 \mathrm{ds}$ & + & $22 / 34$ & Occ. UVT & MoIP & - & + \\
\hline Case 5 & 50 & $\mathrm{~F}$ & $\mathrm{Rec} / 3 \mathrm{Ws}$ & + & $34 / 70$ & UVT (Left eye) & MoIP & - & + \\
\hline Case 6 & 24 & $\mathrm{~F}$ & $\mathrm{Rec} / 5 \mathrm{ds}$ & + & $29 / 52$ & UVT (Left eye) & CLT & - & + \\
\hline Case 7 & 42 & M & $\mathrm{Rec} / 8 \mathrm{ds}$ & + & $24 / 48$ & UVT (bilateral) & SIP & + & + \\
\hline Case 8 & 23 & M & $\mathrm{Rec} / 8 \mathrm{ds}$ & + & $34 / 62$ & Occ. UVT & Pus & + & + \\
\hline Case 9 & 33 & M & $\mathrm{Rec} / 2 \mathrm{Ws}$ & + & $25 / 50$ & Occ. UVT & MoIP & + & + \\
\hline Case 10 & 21 & M & $\mathrm{Rec} / 4 \mathrm{ds}$ & + & $33 / 71$ & UVT (Left eye) & Pus & - & + \\
\hline Case 11 & 31 & $\mathrm{~F}$ & $\mathrm{Rec} / 3 \mathrm{Ws}$ & + & $26 / 53$ & UVT (bilateral) & SIP & + & + \\
\hline Case 12 & 50 & $\mathrm{~F}$ & $\mathrm{Rec} / 2 \mathrm{Ms}$ & - & $22 / 40$ & Rare & MdIP & - & + \\
\hline
\end{tabular}

Abbreviations: ANA: Anti-nuclear antibody; CRP: C-reactive proteins; DD/DD: readings of first and second hours; Ds: Days; MdIP: Mild idiopathic pain; MoIP: Moderate idiopathic pain; Ms: Months; Occ: Occasional (especially in winter); PUs: Peptic ulcers; Rec: Recurrence; SIP: Severe idiopathic pain; SSPT: Self-saliva pathergy test; UVT: Uveitis; Ws: Weeks

to be attracted to a low-grade bacterial infection or foreign body which may be natively mixed with the saliva: probably streptococcus sanguinis.

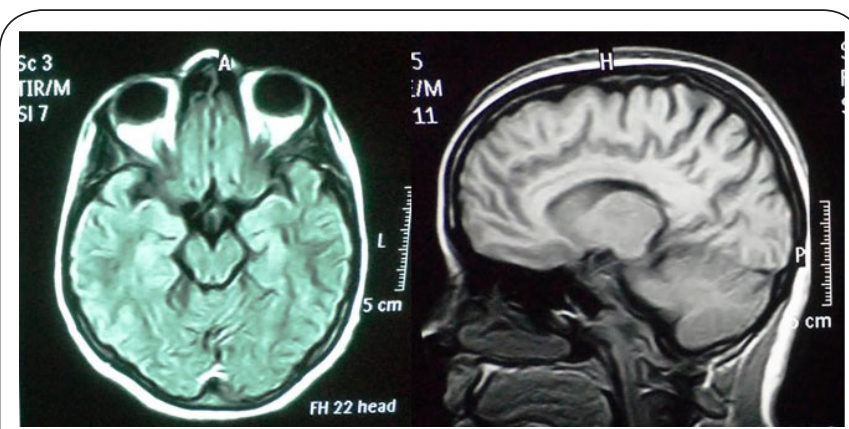

Figure 3. Axial and sagittal sections showing normal brain with no remarkable pathoses.

Table 2. Histological findings in the submitted cases.

\begin{tabular}{|c|c|c|}
\hline & Normal & Behcet's disease \\
\hline $\begin{array}{l}\text { Gross picture of minor } \\
\text { salivary gland }\end{array}$ & Small-sized & Swollen \\
\hline Ruptured blood vessel & Nil & $\begin{array}{l}\text { Evident in } \\
\text { various range }\end{array}$ \\
\hline RBCs extravasation & Nil & Conspicuous \\
\hline Inflammatory infiltrates & Rare & $\begin{array}{l}\text { Periductal/ } \\
\text { perivascular }\end{array}$ \\
\hline Dusty acini & Rare (heavy smokers) & $\begin{array}{l}\text { Featured a } \\
\text { remarkable } \\
\text { range, including } \\
\text { non-smokers }\end{array}$ \\
\hline CD68 & Negative & Positive $(++)$ \\
\hline CD16b & Negative & Positive (+) \\
\hline CD34 & Negative & Positive $(+++)$ \\
\hline Cathepsin-K & Negative & Negative \\
\hline
\end{tabular}

The overall picture of vascular interference, dusty acini and periductal infiltrates was not traced in any of the control group. This histological picture may be characteristic of ABS. The focal inflammatory infiltration is totally less abundant than lymphepitelial infiltrations of Sjögren's and Mikulicz. Neither epimyoepithelian islands nor germinal centers were observed (Figures $\mathbf{4}$ and $\mathbf{5}$ ).

\section{Immunohistochemical findings}

With regard to immunohistochemistry (IHC), CD68 expression manifested crowding of macrophages on the normally appearing acini. It is expected to attack the strands of the infiltrating streptococcus sanguinis. All cases have expressed focal positivity which ranged from moderate to strong expression (Figures 6 and 7).

Expression of CD16b revealed an aggregation neutrophils whose infiltration was mostly perivascular and periductal. All cases have encountered focal positivity which ranged from moderate to strong expression (Figure 8).

Staining of CD34 revealed an aggregation of endothelial vessels and increased intervening vascularity in comparison with the sparse expression in normal glandular (Figures 9 and 10). The twelve cases of ABS as well as the twelve archival cases were negative for Cathepsin- $K$, a marker of a cysteine proteinase expressed by epithelioid and giant multinucleated cells allowing for detection of entrapped microgranulomatus areas [13], excluding Crohn's syndrome and other granulomatous diseases.

\section{Discussion}

Behcet's disease is a mysterious multisystemic disorder characterized by recurrent involvement of mucocutaneous, ocular, intestinal, vascular, and/or nervous system organs. Previously, the positivity of "pathergy test" was reported to 


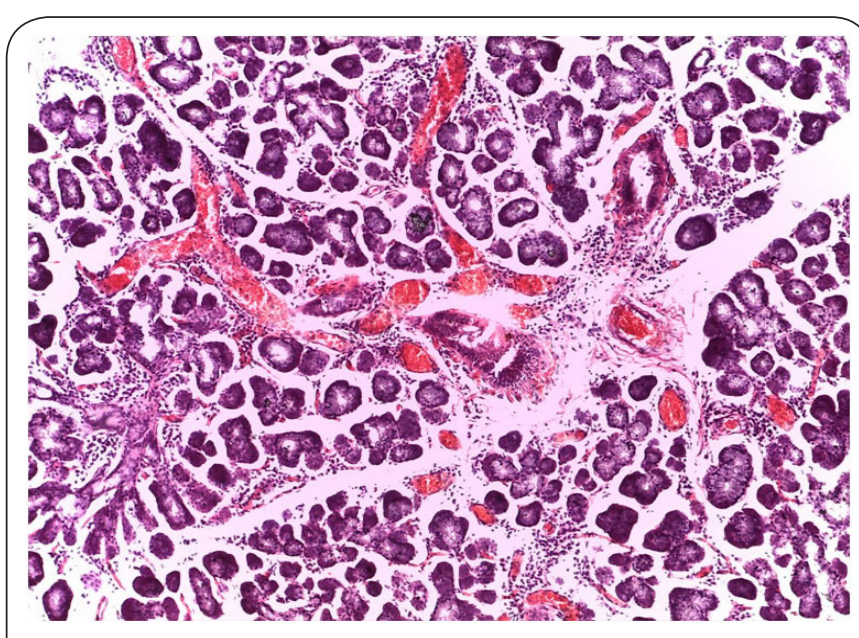

Figure 4. H\&E photomicrograph showing hemorrhage and vascular rupture along with darker dusty acini and periductal inflammatory infiltrates (original magnification 10x).

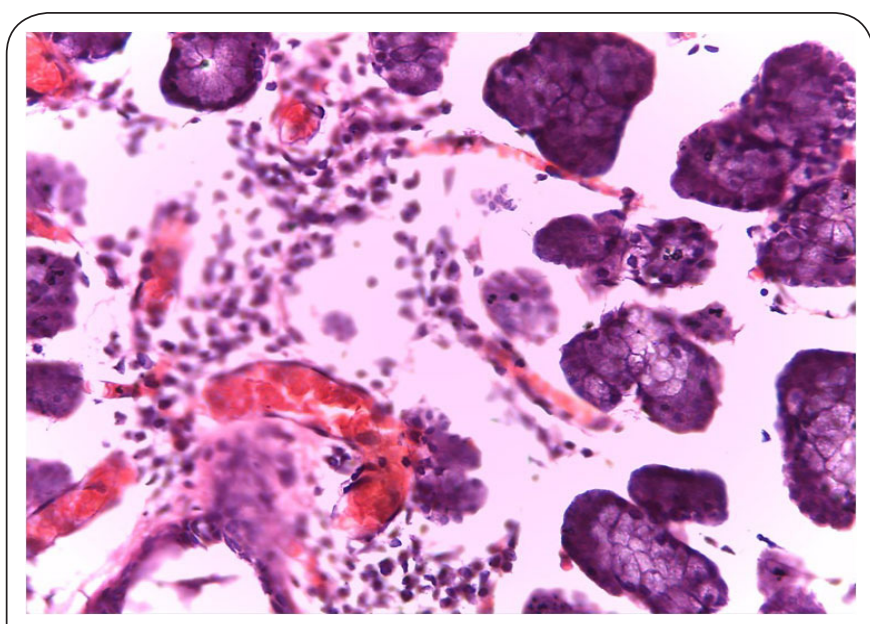

Figure 5. Photomicrograph showing hemorrhage, extravasated RBCs and inflammatory-infiltrate-laden acini "dusty acini" (H\&E stained, original magnification 40x).

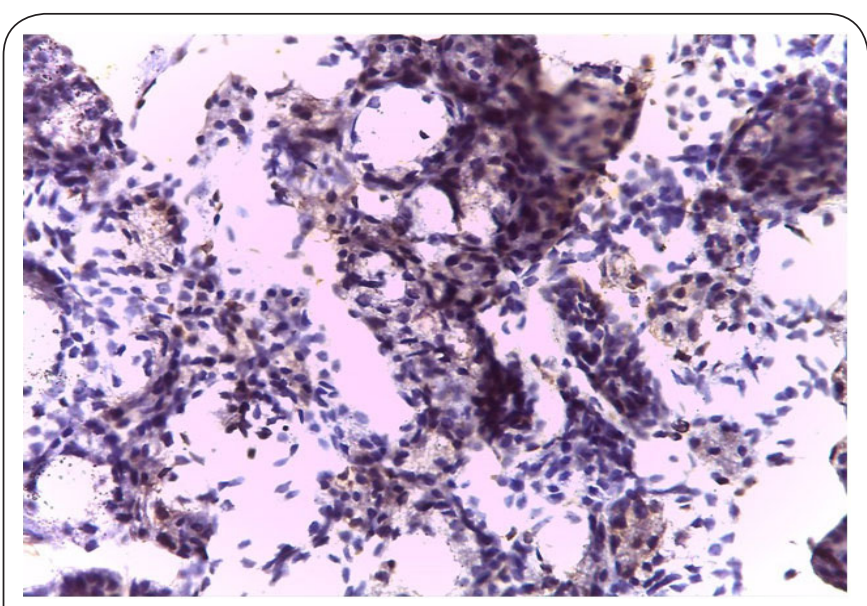

Figure 6. Expression of CD68 in the salivary glandular tissue (original magnification 40x).

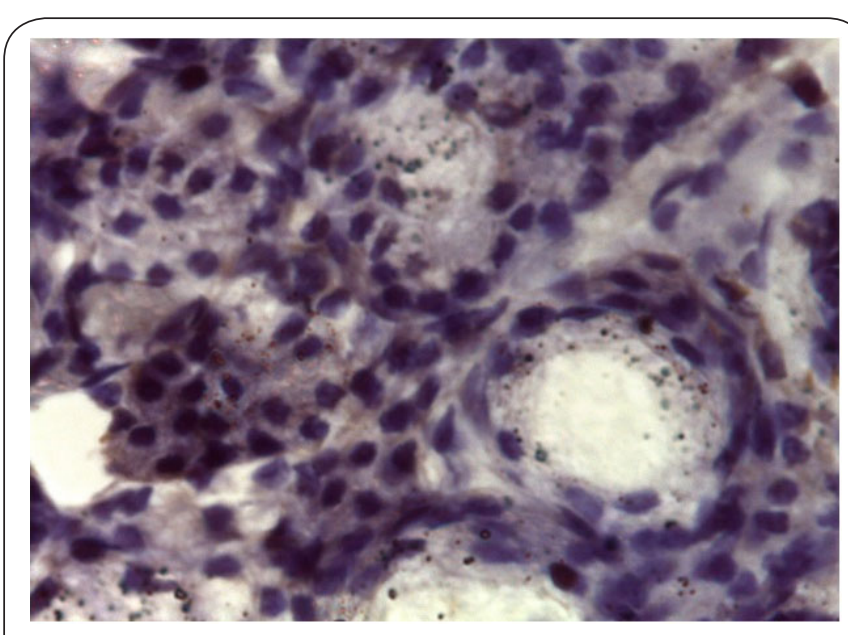

Figure 7. Expression of CD68 in the salivary glandular tissue: the macrophages-laden acini are recognizable (original magnification 100x).

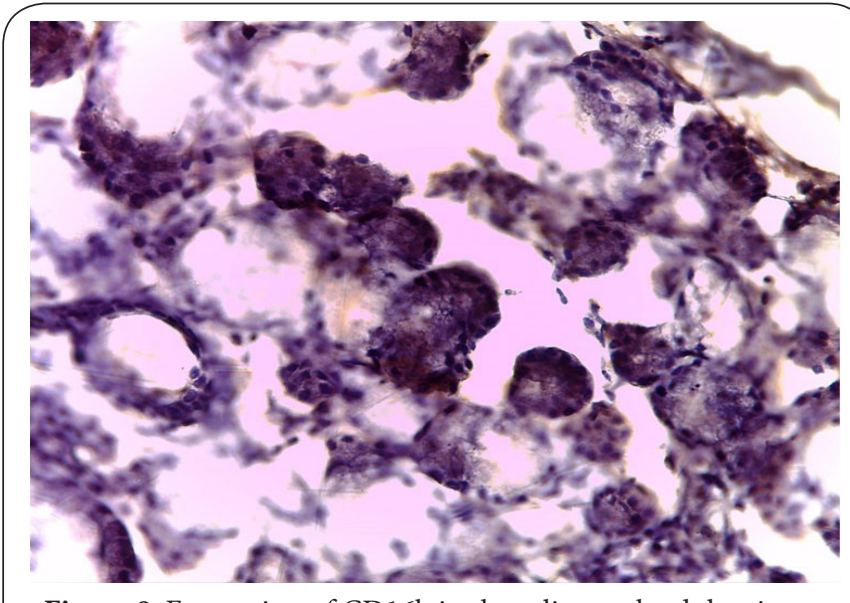

Figure 8. Expression of CD16b in the salivary glandular tissue (original magnification 100x). Neutrophilic positivity is grossly expressed.

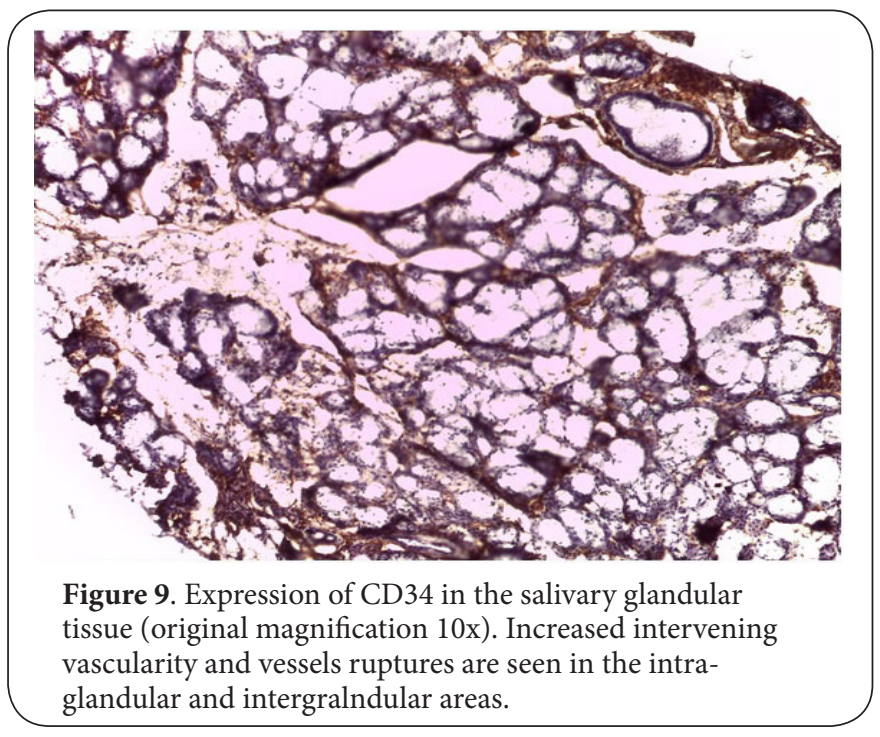




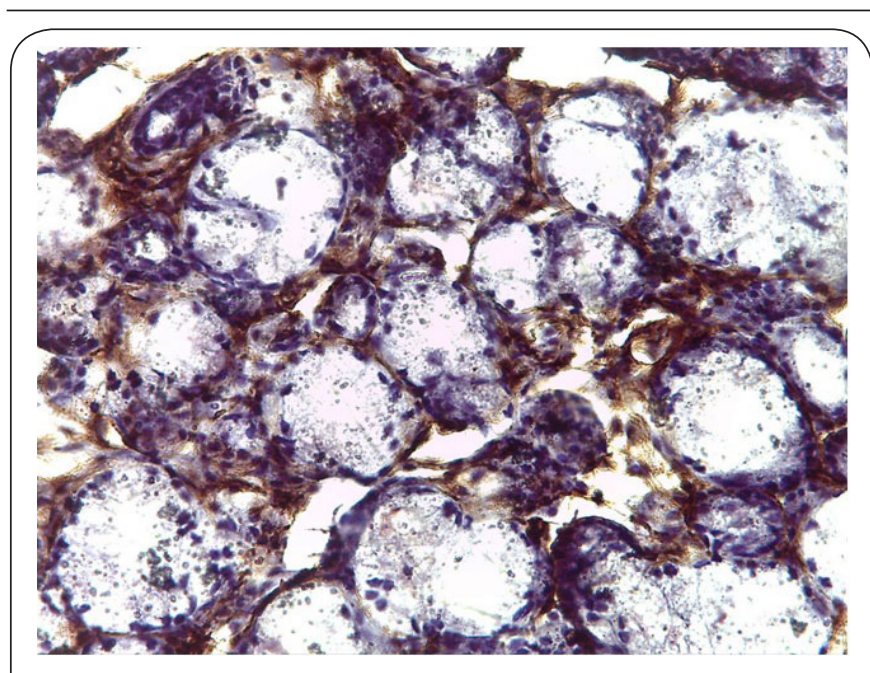

Figure 10. Expression of CD34 in the salivary glandular tissue (original magnification 100x).

be related to the possession of HLA-B51 gene in ABS patients, more likely involved in the hyperactivity of neutrophils, and considered a reliable diagnostic finding [11]. In this study, multiple systems were involved in all submitted cases. The least to observe were ocular and neurological manifestations.

Interestingly, some studies have reported increased neutrophil function in HLA-B51-positive ABS patients $[14,15]$. However, the specificity and sensitivity of this test, along with its variable expression by patients all over the world, suspected its validity [11].

The role of autoimmunity has been widely discussed in the pathogenesis of the disease $[16,17]$. However, anti-nuclear antibody (ANA) positivity, anti-Ro, and anti-La antibodies, which are usually found in autoimmune disorders, were frequently negative in $\mathrm{ABS}$. Several studies have demonstrated the presence of anti-endothelial antibodies, anti-lymphocytic antibodies, and heat-shock protein 60 (HSP60) in ABS; however, these antibodies have not been strongly associated with the disease [18].

Neutrophils are hyperactive in ABS, with increased chemotaxis, phagocytosis, superoxide production and myeloperoxidase expression and produce several cytokines, including IL-12 [19,20]. Vasculitis-related alterations have been observed in biopsy specimens of oral aphthae, genital ulcers, and skin lesions [21]. As vasculitis is considered to be a major component involved in the pathogenesis of $A B S$, it is recommended that the disease should be evaluated under systemic vasculitides [22]. Nearly $40 \%$ to $70 \%$ of patients also have positive anti-Saccharomyces cerevisiae antibodies (ASCA), which are proportional to the disease severity. The ASCA positivity is higher in patients with $C D$ than $A B S[23,24]$.

Clinically, our cases suffered from recurrent oral ulcers. These ulcers are classified as large, small, or herpetiform, based on their size. They were extremely painful and involved the buccal mucosa, labial mucosa, tongue, soft and hard palate, and the pharynx. The incidence of genital ulcers with scar formation was relatively lower compared with persistently recurrent oral ulcers. Genital ulcers were reported in the scrotum and penis in men, while vulva, vagina, and cervix were frequently reported in women. Some cutaneous manifestations were observed including acne-like papules, pustules, pseudofolliculitis, and erythema nodosum-like lesions. These findings go hand in hand with the reported signs and symptoms in the medical literature $[25,26]$.

Epidemiologically speaking, the prevalence of Behçet's disease is 7.6 per 100,000 persons in Egypt while Turkey demonstrates the highest prevalence of ABS in the world, with up to 421 per 100,000 persons affected. Iran, Israel, northern China, and Korea follow with the next highest prevalence. The countries with the lowest prevalence are the UK, Spain, Sweden, Portugal, and the USA, ranging from 0.3 to 6.4 per 100,000 individuals [27].

The pathergy phenomenon is the development of an aseptic non-specific hyper-reactivity to minor trauma which varies from an indurated erythema to pustular formation on the skin. The test is based on the principle of using a 21-25-gauge needle inserted into the skin. Positive test results show papulopustular lesions in the skin or erythematous reactions of the surrounding tissue within $24-48$ hours $[\mathbf{2 6 , 2 8}]$. In this study, 10 cases were positive for injecting sterilized self-saliva subcutaneously.

Histologically, neutrophilic infiltrations, lymphocyte aggregation of the surrounding vessels and vascular proliferation have been observed in biopsy specimens of oral apthae and genital ulcers in a plethora of ABS cases. Neutrophil-predominating infiltration, abscess formation and vasculitis-related changes may be present in skin lesions. Aggregation of lymphocytes, neutrophils, and eosinophils as well as edema and leukocytoclasia occur in the pathergy test site within the first 12 hours. In large vessel involvement, perivascular neutrophillic infiltration is evident along with a strong liability of developing aneurysms or transmural necrosis [29-31].

Adamandiades-Behcet's syndrome has no obvious glandular pathoses. Neither endocrine nor exocrine glands were reported to be encompassed. Yet, the minor salivary glands were observed to be usually palpable and hyperplastic. Many patients have reported aching pain in the lower lip which was in proximity of ulcerative mucosa $(5 / 12)$ or pertaining to normal mucosa (7/12). Some patients consented to examine 2-3 minor salivary glands and the findings were consistent in all salivary glands biopsies in ABS. This has nothing to do with the nearby ulcers, if any.

Characteristic to the histological examination of the minor salivary speciemens was the conspicuous increased in vascularity, in contrast to normal mucosa whose vascular components were inconspicuous. Areas of massive hemorrhage as well as intervening extravasation of RBCs were evident, suggesting deterioration of the feeding blood vessels 
Bacem A.E. Ottoman, Pathology Discovery 2015,

and capillaries. Evident in histological fields was also the appearance of the so-called "dusty acini", recapitulating the guise of the dust cells in smoking alveolitis. The inflammatory infiltrate are expected to be attracted to a low-grade bacterial infection or foreign body which may be natively mixed with the saliva: most probably streptococcus sanguinis.

Uveitis, aneurysms and CNS responses may classically imply a progressive course of the disease. The immunopathogenic retinal-s antigen, which is localized to the photoreceptor area of the retina, causes certain forms of uveitis. The recurrent uveitis is highly striking for liability of visual loss especially in the left eye. Behçet's experts should become far more attentive to the effect of psychological stress on skin disorders, not only for the benefit of their patients but also because the skin serves as a very clinically relevant model system for exploring the neuroimmunology of peripheral and central stress responses [32-34]. In this study, uveitis was the commonest ocular manifestation especially in the left eye.

\section{Conclusion}

Aside from diagnosing lymphepithelial and systemic granulomatous diseases, the biopsy of the minor salivary glands of normally appearing labial mucosa may be informative and useful in diagnosing Behçet's disease in its various stages. This holds true including indolent and mitigated phases, especially with the use of the aforementioned immunohistochemical markers. With the introduction of this diagnostic protocol, any average practitioner may establish the diagnosis of ABS and distinguish it easily from Crohn's disease. This study, too, supports the validity of using sterilized self-saliva in the "Pathergy test".

\section{Competing interests}

The author declares that he has no competing interests.

Publication history

Senior Editor: Takuji Tanaka, Gifu University, Japan.

Received: 27-Apr-2015 Final Revised: 16-Jun-2015

Accepted: 26-Jun-2015 Published: 03-Jul-2015

\section{References}

1. Sakane T, Takeno M, Suzuki N and Inaba G. Behcet's disease. N Eng/ J Med. 1999; 341:1284-91. | Article | PubMed

2. Behçet $H$. Über rezidivierende, aphthose, durch ein virus verursachte Geschwüre am Mund, am Auge und an den Genitalien. Dermatol Wochenschr. 1937; 105:1152-7.

3. Behçet $\mathrm{H}$. Considerations sur les lesions aphteuses de la bouche et des parties genitals, ainsi que sur les manifestations oculaires d'origine probablement virutique et observations concernant leur foyer d'infection. Bull Soc Fr Dermatol Syphiligr. 1938; 45:420-33.

4. Behçet $\mathrm{H}$. Einige Bemerkungen zu meinen Beobachtungen über den Tri Symptomen komplex. Med Welt. 1939; 35:1222-7.

5. Pay S, Simsek I, Erdem H and Dinc A. Immunopathogenesis of Behcet's disease with special emphasize on the possible role of antigen presenting cells. Rheumatol Int. 2007; 27:417-24. | Article | PubMed

6. Kulaber A, Tugal-Tutkun I, Yentur SP, Akman-Demir G, Kaneko F, Gul A and Saruhan-Direskeneli G. Pro-inflammatory cellular immune response in Behcet's disease. Rheumatol Int. 2007; 27:1113-8. | Article | PubMed
7. Emmi G, Silvestri E, Squatrito D, D’Elios MM, Ciucciarelli L, Prisco D and Emmi L. Behcet's syndrome pathophysiology and potential therapeutic targets. Intern Emerg Med. 2014; 9:257-65. | Article I PubMed

8. Yazici $\mathrm{H}$ and Yazici Y. Criteria for Behcet's disease with reflections on all disease criteria. J Autoimmun. 2014; 49:104-7. | Article I PubMed

9. Evereklioglu C. Current concepts in the etiology and treatment of Behçet disease. Survey ophthalmol. 2005; 50:297-350. I Article

10. Criteria for diagnosis of Behcet's disease. International Study Group for Behcet's Disease. Lancet. 1990; 335:1078-80. | PubMed

11. Kaneko F, Togashi A, Nomura E and Nakamura K. A New Diagnostic Way for Behcet's Disease: Skin Prick with Self-Saliva. Genet Res Int. 2014; 2014:581468. | Article | PubMed Abstract | PubMed Full Text

12. Khalidi HS, Medeiros LJ, Chang KL, Brynes RK, Slovak ML and Arber DA. The immunophenotype of adult acute myeloid leukemia: high frequency of lymphoid antigen expression and comparison of immunophenotype, French-American-British classification, and karyotypic abnormalities. Am J Clin Pathol. 1998; 109:211-20. | Article | PubMed

13. Diaz A, Willis AC and Sim RB. Expression of the proteinase specialized in bone resorption, cathepsin $\mathrm{K}$, in granulomatous inflammation. $\mathrm{Mol}$ Med. 2000; 6:648-59. | PubMed Abstract | PubMed Full Text

14. Takeno M, Kariyone A, Yamashita N, Takiguchi M, Mizushima Y, Kaneoka $\mathrm{H}$ and Sakane T. Excessive function of peripheral blood neutrophils from patients with Behcet's disease and from HLA-B51 transgenic mice. Arthritis Rheum. 1995; 38:426-33. | Article | PubMed

15. Kaneoka H, Furukawa H, Takeno M, Mizushima Y and Sakane T. HLA-B51 involved in the hyperfunction of peripheral blood neutrophils from patients Behcet's disease. In: Wechsler B, Godeau P, editors. Behçet's Disease Amsterdam: Excerpta Medica. 1993; 29-32.

16. Direskeneli H. Autoimmunity vs autoinflammation in Behcet's disease: do we oversimplify a complex disorder? Rheumatology (Oxford). 2006; 45:1461-5. | Article I PubMed

17. Yazici $H$. The place of Behcet's syndrome among the autoimmune diseases. Int Rev Immunol. 1997; 14:1-10. I Article I PubMed

18. Kibaroglu A, Eksioglu-Demiralp E, Akoglu T and Direskeneli H. T and NK cell subset changes with microbial extracts and human HSP60-derived peptides in Behcet's disease. Clin Exp Rheumatol. 2004; 22:S59-63. I Pdf I PubMed

19. Verity DH, Wallace GR, Vaughan RW and Stanford MR. Behcet's disease: from Hippocrates to the third millennium. Br J Ophthalmol. 2003; 87:1175-83. | Article | PubMed Abstract | PubMed Full Text

20. Zierhut M, Mizuki N, Ohno S, Inoko H, Gul A, Onoe K and Isogai E. Immunology and functional genomics of Behcet's disease. Cell Mol Life Sci. 2003; 60:1903-22. | Article | PubMed

21. Chun SI, Su WP and Lee S. Histopathologic study of cutaneous lesions in Behcet's syndrome. J Dermatol. 1990; 17:333-41. I Article I PubMed

22. Jennette JC, Falk RJ, Bacon PA, Basu N, Cid MC, Ferrario F, Flores-Suarez LF, Gross WL, Guillevin L and Hagen EC et al. 2012 revised International Chapel Hill Consensus Conference Nomenclature of Vasculitides. Arthritis Rheum. 2013; 65:1-11. | Article | PubMed

23. Filik $L$ and Biyikoglu I. Differentiation of Behcet's disease from inflammatory bowel diseases: anti-Saccharomyces cerevisiae antibody and anti-neutrophilic cytoplasmic antibody. World J Gastroenterol. 2008; 14:7271. | Article | PubMed Abstract | PubMed Full Text

24. Choi CH, Kim TI, Kim BC, Shin SJ, Lee SK, Kim WH and Kim HS. AntiSaccharomyces cerevisiae antibody in intestinal Behcet's disease patients: relation to clinical course. Dis Colon Rectum. 2006; 49:1849-59. | Article | PubMed

25. Shang Y, Han S, Li J, Ren Q, Song F and Chen $H$. The clinical feature of Behcet's disease in Northeastern China. Yonsei Med J. 2009; 50:630-6. I Article | PubMed Abstract | PubMed Full Text

26. Tursen U, Gurler A and Boyvat A. Evaluation of clinical findings according to sex in 2313 Turkish patients with Behcet's disease. Int J Dermatol. 2003; 42:346-51. | Article | PubMed

27. Yurdakul S and Yazici Y. Epidemiology of Behçet's syndrome and regional differences in disease expression. In: Yazici Y, Yazici H, editors. Behçet's 
Bacem A.E. Ottoman, Pathology Discovery 2015,

http://www.hoajonline.com/journals/pdf/2052-7896-3-5.pdf

syndrome. $\mathbf{1}^{\text {st }}$ ed. New York: Springer. 2010; 35-52.

28. Ozen S. Vasculopathy, Behcet's syndrome, and familial Mediterranean fever. Curr Opin Rheumatol. 1999; 11:393-8. | Article | PubMed

29. Chun SI, Su WP and Lee S. Histopathologic study of cutaneous lesions in Behcet's syndrome. J Dermatol. 1990; 17:333-41. | Article | PubMed

30. Matsumoto T, Uekusa T and Fukuda Y. Vasculo-Behcet's disease: a pathologic study of eight cases. Hum Pathol. 1991; 22:45-51. | Article | PubMed

31. Demirkesen C, Oz B and Göksal S. Behçet's Disease: Pathology. $1^{\text {st }}$ ed. In: Yazici Y, Yazici H, editors. Behçet's Syndrome (NY): Springer. 2010; 215-43.

32. Tursen U. Pathophysiology of the Behcet's Disease. Patholog Res Int. 2012; 2012:493015. | Article | PubMed Abstract | PubMed Full Text

33. de Smet MD, Bitar G, Mainigi S and Nussenblatt RB. Human S-antigen determinant recognition in uveitis. Invest Ophthalmol Vis Sci. 2001; 42:3233-8. | Article | PubMed

34. Arck PC, Slominski A, Theoharides TC, Peters EM and Paus R. Neuroimmunology of stress: skin takes center stage. J Invest Dermatol. 2006; 126:1697-704. | Article | PubMed Abstract | PubMed Full Text

\section{Ottoman BAE. New histological finding in}

adamandiades-behçet's syndrome. Pathol Discov.

2015; 3:5. http://dx.doi.org/10.7243/2052-7896-3-5 